\title{
Correspondence
}

Effects of culture media on detection of methicillin resistance in coagulase negative staphylococci

We read with interest the report by Milne et $a l^{1}$ on the effects of culture media on the detection of methicillin resistance in coagulase negative staphylococci (CNS). We agree with their conclusions that the incorporation of salt in Columbia agar is the most reliable culture medium for the detection of methicillin resistance in CNS by disc testing.

The UK National External Assessment Scheme for Microbiology (NEQAS) has shown that "generally most laboratories can recognise methicillin resistance in Staphylococus aureus but have more problems with Staphylococcus epidermidis" (Snell, personal communication). Some laboratories may be seriously underestimating the percentage of isolates of CNS that are resistant to methicillin.

We examined 248 CNS for susceptibility to methicillin by disc testing using three different methodologies. Method 1 used Columbia agar with $2 \%$ salt added (CA + $2 \%$ salt) whilst method 2 used Mueller Hinton agar containing $2 \%$ salt $(\mathrm{MH}+2 \%$ salt); in both methods incubation was at $35^{\circ} \mathrm{C}$ for 24 hours. Method 3 incorporated Diagnostic Sensitivity Test (DST) agar plus $1 \%$ lysed blood, incubated at $30^{\circ} \mathrm{C}$ for 21 hours. Strains showing equivocal results were further examined by plate MIC using the three media and respective incubation conditions.

Of the 248 strains tested, 36 were excluded because they were novobiocin resistant and two more were excluded because they were not identified on the ATB 32 Staph system (bioMerieux SA). Of the remaining 210 stains, the MIC results showed $107(51 \%)$ to be resistant to methicillin. The results for the three methodologies are shown in the table.

The method using Columbia agar incorporating $2 \%$ salt incubated at $35^{\circ} \mathrm{C}$

\begin{tabular}{|c|c|c|c|}
\hline Method & $\begin{array}{l}\text { Number } \\
\text { of } \\
\text { CNS } \\
\text { strains } \\
\text { resistant } \\
\text { to } \\
\text { methicillin } \\
(n=107)\end{array}$ & $\begin{array}{l}\text { Number } \\
\text { of } \\
\text { CNS } \\
\text { strains } \\
\text { sensitive } \\
\text { to } \\
\text { methicillin } \\
(n=103)\end{array}$ & $\begin{array}{l}\text { Number } \\
\text { of } \\
\text { sensitive } \\
C N S \\
\text { strains } \\
\text { showing } \\
\text { false } \\
\text { resistance } \\
\text { to } \\
\text { methicillin }\end{array}$ \\
\hline $\begin{array}{c}\mathrm{CA}+ \\
2 \% \text { salt } \\
\mathrm{MH}+\end{array}$ & $107(100 \%)$ & 101 & 2 \\
\hline $\begin{array}{l}2 \% \text { salt } \\
\text { DST ages }+ \\
1 \% \\
\text { lysed blood }\end{array}$ & $93(87 \%)$ & 114 & 3 \\
\hline
\end{tabular}

detected all the resistant strains, but two sensitive strains were identified as resistant. This medium is clearly superior to both the other methods tested, although variations of methods based on DST incubated at $30^{\circ} \mathrm{C}$ appear to be the most common in use in the UK for determining methicillin sensitivity (Snell, personal communication).
Methods for determining methicillin sensitivity of staphylococci have undergone development since the first resistant strains were reported, as they were originally developed for $S$ aureus; the same modifications are now being applied for CNS. However, CNS grow less luxuriantly than $S$ aureus and the resistant subpopulation is smaller, making it harder to detect methicillin resistance. ${ }^{2}$ Where laboratories incorporate salt in their media for sensitivity testing, a concentration of $5 \%$ is usually used, but this concentration is not well tolerated by staphylococci. ${ }^{3}$ Previous investigations showed that $2 \%$ salt provides an osmotically supportive medium and, in conjunction with Columbia agar, encourages enhanced growth and therefore more clearly demonstrates methicillin resistance. These results are also in general agreement with those of other studies ${ }^{4}$ and we recommend the use of Columbia agar incorporating $2 \%$ salt for the detection of methicillin resistance in CNS.

RJD SCOTT J MORGAN

VS PETHER

Public Health Laboratory, Musgrove Park Hospital, Taunton, Somerset TAI SDB JF RICHARDSON

Staphylococcus Reference Laboratory, Central Public Health Laboratory, 61 Colindale Avenue, London NW9 $5 H T$ RHF BOSLEY

Eli Lilly and Co. Ltd, Kingsclere Road Basingstoke, Hampshire RG21 $2 \mathrm{XA}$

1 Milne LM, Crow MR, Emptage AGM, et al. Effects of culture media on detection of methicillin resistance in Staphylococcus aureus and coagulase-negative staphylococci by disc diffusion methods. F Clin Pathol by disc diffusion

2 Lowy FD, Chang DS, Aning V, et al. Reliability of in vitro susceptibility tests for detecting coagulase-negative staphylococcal resistance to penicillinase-resistant semisynthetic penicillins. $₹$ Clin Microbiol 1983;18: 1122-6.

3 Barber M. Naturally occurring methicillinresistant staphylococci. $\mathcal{f}$ Gen Microbio 1964;35:183-90.

4 Law D, Megson GM, Keaney MGL, et al. The influence of salt concentration on the detection of methicillin resistance in coagulase-negative staphylococci. $\mathcal{F}$ Antimicrob lase-negative staphylococci.
Chemother 1992;30:603-14.

\section{Diagnosis of Helicobacter pylori in} biopsy specimens

I read with interest the report by Veenendaal et al who showed that a 24 hour delay and storage of antral biopsy specimens in physiological saline solution did not alter the positive culture rate of Helicobacter pylori. ${ }^{1}$ However, I feel that the definition they have used for the diagnosis of $H$ pylori infection may be misleading, if used without consideration. As they state, it is clear that culture is a $100 \%$ specific, though "probably not the most sensitive test" for the identification of $H$ pylori infection. Their case with a positive serology and histology result, but with a negative culture seems to justify this view. Concerning their remaining two positive cases, my opinion is that microscopic identification of an $H$ pylori-like organism in a haematoxylin and eosin stained biopsy specimen alone cannot be accepted as a diagnostic criterion for infection. Haematoxylin and eosin staining is not a generally accepted tool for demonstrating the micro-organism as it is not sufficiently sensitive, though it is ideal for indicating antral gastritis. It is not suitable for detecting early colonisation of the mucosa by the bacterium. Stains such as Wright-Giemsa, Brown-Hopps, or WarthinStarry silver stain are more commonly accepted for this purpose because they are more sensitive. ${ }^{2}$ In routine diagnostic work, however, it is advisable to use two of the tests that are not fully specific, as mentioned by Neithercut et al in their discussion. $^{3}$ One of these may be histological, preferably using special staining methods. Even withdrawal of the two cases where only histology was positive would not influence the result described in the paper. G CSERNI Department of Pathology, Szent-Györgi Medical University, Szeged, Hungary

1 Veenendaal RA, Lichtendahl-Bernards AT, Peña AS, et al. Effect of transport medium and transportation time on culture of Helicobacter pylori from gastric biopsy specimens. F Clin Pathol 1993;46:561-3.

2 Madan E, Kemp J, Westblom TU, et al. Evaluation of staining methods for identifying Campylobacter pylori. Am $\mathcal{F}$ Clin Pathol ing Campylobacte

3 Neithercut WD, Rowe PA, El Nujumi AM, et al. Effect of Helicobacter pylori infection on intragastric urea and ammonium concentrations in patients with chronic renal failure. $\mathcal{F}$ Clin Pathol 1993;46:544-7.

Drs Veenendaal and Lichtendahl-Bernards comment:

Although the results of our study as indicated by the correspondents were not influenced by the definition of Helicobacter pylori infection used, their comment addresses an important point. ${ }^{1}$

There is no general agreement as to which tests should be used as the gold standard in the diagnosis of gastric $H$ pylori infection. In a recent (unpublished) study we found the combination of histology (haematoxylin and eosin stain) and culture as a definition of $H$ pylori infection superior with regard to sensitivity when compared with either test alone (121 patients culture positive, 125 patients positive by histology and 137 patients positive by histology or culture, or both). These findings almost matched the results of a previous validated sensitive and specific enzyme linked immunosorbent assay (ELISA), ${ }^{2}$ for IgG $H$ pylori antibodies, used in the same population (143 positive patients). Other authors also confirmed the diagnostic value of histology ${ }^{34}$ and haematoxylin and eosin staining methods. ${ }^{5}$ However, experience with the test used is essential and here we agree with the correspondents.

In our pathology department there is a long standing interest and experience in the detection of $H$ pylori and its associated gastritis. When in doubt about the diagnosis, especially after treatment when organisms are infrequent or absent in the presence of chronic gastritis, additional staining techniques (Giemsa or Warthin-Starry) are occasionally necessary. This did not apply to our study. We therefore consider our "good standard" appropriate.

As pointed out in our article, we feel that culture is important for routine diagnostic 
work, because it allows antimicrobial susceptibilities (metronidazole, clarithromycine to be determined, and we would not replace it for a specific test that was not fully specific as suggested by the correspondents.

1 Veenendaal RA, Litchendahl-Bernards AT, Peña AS, et al. Influence of transport medium and transportation time on culture of Helicobacter pylori from gastric biopsies. $\mathcal{F}$ Clin Pathol 1993;46:561-3.

2 Peña AS, Endts HPh, Offerhaus CJA Hoogenboom-Verdegaal A, et al. Value of serology (ELISA and Immunoblotting) for the diagnosis of campylobacter pylori infection. Digestion 1989;44:131-41.

3 Lin SK, Lambert JR, Schembri $M$, et al. A comparison of diagnostic tests to determine Helicobacter pylori infection. $\mathcal{f}$ Gastroenterol Hepatol 1992;7:203-9.

4 Veldhuyzen van Zanten SJO, Tytgat KMAJ, de Gara CJ, et al. A prospective comparison de Gara CJ, et al. A prospective comparison
of symptoms and five diagnostic tests in patients with $H$ pylori positive and negative dyspepsia. Eur $\mathcal{f}$ Gastroenterol Hepatol 1991; 3:463-8.

5 Marshall BJ. Practical diagnosis of Helicobacter pylori. In: Marshal BJ, McCallum RW, Guerrant RL, eds. Helicobacter pylori in peptic ulceration and gastritis. Boston: Blackwell Scientific Publications 1991:139-59.

\section{Measurement of medical staff overload}

Dr Bignardi ${ }^{1}$ is correct in his conclusion that it is difficult to measure medical staff workload and requirements in microbiology departments. The current guidelines of the Royal College of Pathologists for consultant staffing suggest that for central laboratories in district general hospitals serving a population of approximately 250000 there should be at least two consultant medical microbiologists. ${ }^{2}$ A number of districts do not provide such staffing and cases need to be developed to persuade managers to provide appropriate cover. "Population served" is a crude measure of workload, even if referral patterns do not distort the picture. It is also clear that hospital bed numbers are not directly related to laboratory activity; indeed, for some hospitals reducing bed numbers has resulted in an increase in laboratory tests from outpatients, day cases, and GPs. Numbers of specimens and the number and nature of tests can be more closely related to laboratory activity and can be made more sophisticated by such systems as WELCAN, but these are not a measure of medical input; neither are they a measure of the quality of a microbiology service. Particular problems in measuring consultant microbiologist input are the contributions to core activities of the hospital(s) and clinics served-activities such as hospital infection control, policies for infected waste, chemical disinfection-and the general provision of advice on the management of infected patients. The latter aspects depend to a large extent on the case mix profile of the units served: intensive care units, special care baby units and oncology wards make particularly heavy demands on medical microbiologists. Although these matters are generally clear in principle, the allocation of numerical factors to reflect the workload has proved to be very difficult. Some of the problems of consultant staffing levels have been discussed in a recent article in $A C P$ $N_{e w s}{ }^{3}$ and the Microbiology Specialty Advisory Committee of the Royal College of Pathologists is currently examining this subject. It will not be easy to produce a universally acceptable measure, but the prob- lems must be addressed in order to try to achieve a composite workload definition that reflects the range of input required of a consultant microbiologist.

DR DAVIES Microbiology Specialist Advisory Committee, Royal College of Pathologists, 2 Carlton House Terrace, London SWIY $5 A F$

1 Bignardi GE. How many microbiologists are needed? $\mathcal{C}$ Clin Pathol 1993;46:1051-2.

2 Royal College of Pathologists. Medical and scientific staffing of national health service pathology departments. London: Roya College of Pathologists 1992:1-11.

3 Workload figures: whose norms are they anyway? ACP News 1993:11-12.

Dr Bignardi comments:

I welcome the interest by the Microbiology Specialist Advisory Committee of the Royal College of Pathologists: eliciting such interest was the main purpose of my report. In my opinion the current guidelines by the Royal College of Pathologists for consultant staffing in microbiology are so impractical that they cannot be implemented by the College itself. This is demonstrated by the fact that, during the period of my study, four job descriptions for single-handed consultants were approved by the College despite the fact that the respective populations exceeded 250000 (the College recommends two consultants for departments serving a population of approximately 250 000). According to $\mathrm{my}$ analysis, the case for a second full-time consultant microbiologist was very strong in two of these four hospitals.

One would hope that if a formula based on the weighted number of beds and specimens (and perhaps on other factors) was sanctioned and policed by the College, at the least the worst cases of understaffing could be eliminated. Since writing my report I have noticed some important trends: the overall number of both consultants and junior doctors in microbiology seems to be decreasing, many pathology departments have been asked to take substantial cuts in their budget over the next years, and the NHS Management Executive has commissioned a strategic review of pathology services which might throw the door open to more pathology privatisations.

Given the current political climate, I think it most important that we try to identify and quantify the minimum medical staff requirement for a good quality service in microbiology.

\section{Necrotising granulomas of the uterine corpus}

We read with interest the report by Drs Akosa and Boret of necrotising granulomas of the uterine corpus following Nd YAG laser ablation of the endometrium, ${ }^{1}$ and noted their reference to our original report of peritoneal granulomas following laser ablation. ${ }^{2}$

We subsequently reported the histological findings from four hysterectomy specimens obtained for various indications following Nd YAG laser ablation. ${ }^{3}$ Our findings were essentially the same as those of Akosa and Boret, and we were able to demonstrate by energy dispersive $x$-ray analysis that the black foreign material within the necrotising granulomas consisted largely of aluminium oxide compatible with the known composition of the sapphire laser probe.

We also provided evidence to support the hypothesis that recurrent bleeding following laser ablation is due to inspread of functional endometrium from the tubal ostia and isthmus, ${ }^{45}$ and were disappointed that Akosa and Boret made no comment on the histological appearances of the endometrium away from the obvious laser damage.

Finally, Akosa and Boret refer to the technique as endometrial resection which is in our view not correct, as the use of the $\mathrm{Nd}$ YAG laser is a technique for endometrial ablation.

JHF SMITH

A KENNEDY F SHARP Northern General Hospital,
NHS Trust, Herries Road,
Sheffield S5 $7 A U$ PC REID

Luton and Dunstable Hospital W THURRELI University College Hospital,

1 Akosa AB, Boret F. Necrotising granulomas of the uterine corpus. F Clin Pathol 1993;46: 953-5.

2 Thurrell W, Reid PC, Kennedy A, Smith JHF. Necrotising granulomas of the peritoneum. Histopathology 1991;18:190

3 Reid PC, Thurrell W, Smith JHF, Kennedy A, Sharp F. Nd:YAG laser endometrial ablation: histological aspects of uterine healing. Int $\mathcal{f}$ Gynecol Pathol 1992;11:174-9.

4 Lomano JM. Photocoagulation of the endometrium with the Nd:YAG laser for the treatment of menorhagia: a report of te cases. F Reprod Med 1986;31:148-50.

5 Baggish MS, Baltoyannis P. New techniques for laser ablation of the endometrium in for laser ablation of the endometrium in 1988;159:287-92.

Drs Akosa and Boret comment:

We are grateful to Dr Smith et al for their prompt comment on our short report. This was basically intended to increase awareness among histopathologists of what has become a diagnostic quandary in the absence of adequate clinical information and in view of the increasing use of minimal invasive surgical techniques.

We noted in our report that the abnormalities in the endometrium were either complete or focal, the latter the cause of subsequent bleeding. The residual endometrium, although not stated in our report, was not confined only to the cornu as in the case referred to in the paper by Baggish and Baltoyannis. If one assumes that in every case of endometrial ablation the entire endometrium is destroyed, the hypothesis of inspread may be acceptable: in our experience this is not always the case.

Endometrial resection using laser and endometrial ablation have been and are used interchangeably. Our opening sentence which is now under discussion read "Transcervical resection of the endometrium is a hysteroscopic method of endometrial ablation": this is self-explanatory.

Our literature search was confined to 1989 onwards, which explains why the papers by Baggish and Baltoyannis and Lomano were not cited. As for the paper by Reid et al, we can only assume that at the time of our search it had not been indexed. We have now read all these papers and they 